\title{
Group Decision Making Approach in Karate Agility Test Selection
}

\author{
Mohammad Ebrahim Marjani* \\ Department of Sports Studies \\ Farhangian University \\ Tehran, Iran \\ E-mail: marjan_elm@yahoo.com \\ Soh Kim.Geok \\ Department of Sports Studies \\ University Putra Malaysia \\ Selangor, Malaysia \\ E-mail: kimgeoks@yahoo.com \\ Majid Mojahed \\ Department of Mechanical Engineering \\ University Putra Malaysia \\ Selangor, Malaysia \\ E-mail: majid.mojahed@gmail.com \\ Nur Surayyah M. Abdullah \\ Department of Language and Humanities Education \\ University Putra Malaysia \\ Selangor, Malaysia \\ E-mail: surrayah@educ.upm.edu.my \\ Soheil Marjani \\ Sports Center \\ Universiti of Malaya \\ Kuala Lumpur, Malaysia \\ E-mail: captain_soheil@yahoo.com
}

\begin{abstract}
Karate is one of the most popular martial art styles in the world as well as a popular sport in Iran. Successful performance in karate requires high level of agility that enables the karateka (karate player) to avoid the opponent's attacks, and to assume optimal position for efficient performance of karate techniques. In order to measure agility in karatekas, karate coaches make use of general and available agility tests. However, there are many agility tests but coaches need to know which one is the best test for karatekas. Hence, the purpose of this study is to select the best and most appropriate agility test for karate using Analytic Hierarchy Process (AHP). Data was collected from six karate experts' opinion in order to weight and rank agility tests specifically to select the best agility test. AHP approach allows the weight of each criterion from each expert to be computed in geometrical mean. As a result, based on experts' opinion and using Group AHP approach, the best validated agility test for Karate is Illinois test. This paper describes the usage of the group AHP approach in selecting the most appropriate agility test for karate. It discusses some of the advantages and disadvantages of using this approach. It suggests how the approach can be used in sports research.
\end{abstract}

Keywords: Agility Test, Karate, Multi Criteria Decision Making, Analytic Hierarchy Process.

\footnotetext{
* Corresponding author
} 


\section{Introduction}

Karate is one of the most popular martial art styles in the world (Urban, 1993) as well in Iran (IKF,1995). Currently, more than 180 countries are members of the World Karate Federation (WKF, 1999). In karate, agility (for example, the mobility of the karateka in various directions), contributes greatly to improve performance of the karateka. Good agility enables the karateka to avoid the opponent's attacks and to assume optimal position for efficient performance of karate techniques (Blaevi, Kati, \& Popovi, 2006; Katic, Srhoj, \& Pazanin, 2005).

Agility is the physical ability that enables an individual to rapidly change the body position and direction in a precise manner (Johson, 1988). It is not a single ability but a complex of several abilities (Blume, 1978; Dey, Kar, \& Debray, 2010; Meinel \& Schnabel, 1976). These abilities are primarily dependent upon the coordinative processes of the central nervous system that are important specifically in karate.

To measure agility, there exist some general standard tests (Lacy \& Hastad, 2007). These test results can be used both to motivate self-improvement and help individuals to plan their fitness goals. Test is a tool or instrument of measurement; measurement is a major step in evaluation, and evaluation is an encompassing process, making qualitative decisions based on the quantitative data derived from tests and measurement. Therefore, karate agility test provide objective measure of agility ability among karateka.

Agility is an important component of fitness for success in a wide variety of sports. It assumes a vital role in predicting the success of individuals in sport and physical activity (Lacy \& Hastad, 2007). According to Sheppard, et al., (2006), agility is a multi-factorial physical ability affected by explosive strength, speed, balance, muscular coordination, and flexibility. Besides, agility tests are best used for diagnostic purpose to determine which karateka is the most agile, and which one requires more additional practice to perform better. A good agility test depends on strength, speed, coordination, and dynamic balance (Chelladurai, 1976; Miller, 2006).

Many researchers have reported that agility is the most discriminating factor of performance among players (Reilly, Williams, Nevill, \& Franks, 2000) and has a key role in improving performance (Pauole, Madole, Garhammer, Lacourse, \& Rozenek, 2000). It is the most critical factor for sport competitors in fighting off the competition from their rivals in karate. For instance, a karateka requires changing direction speed and position in response to the movements of adversary and must be of a dominant agility to an opponent (Blaevi et al., 2006). As mentioned earlier, agility is the most critical factor for sport competitors in karate. Tests of agility are best used for the purpose of diagnostic and classification of players. However, there is no karate-specific agility test to achieve the above goals.

Based on previous studies (Ellis et al., 2000; Harman, Garhammer, \& Pandorf, 2000; Hasegawa et al., 2002; Kirkendall, 2000; Lacy \& Hastad, 2007; Miller, 2006; Pollitt, 2003; Vescovi \& McGuigan, 2008), the researcher has selected eight general and validated agility tests. These are referred to as alternatives according to AHP approach. These alternatives include: Illinois test (Cureton, 1951), Zigzag test (Barrow, 1953), SEMO agility test (Kirby, 1971) Shuttle run agility and 505 agility test (AAHPER,1976), Side-Stepping (Johnson \& Nelson, 1986), Agility T-test (Semenick, 1990) and Hexagon test (Roetert, Piorkowski, Woods, \& Brown, 1995) due to their specific characteristics in line with the main concern of the study. In addition, eight components of agility, which are named criteria based on AHP approach, are as follows: speed, strength, power, coordination ,balance, reaction time, flexibility and body mechanism (Chelladurai, 1976; Sheppard \& Young, 2006).

Since, AHP is one of the most validated Multi Criteria Decision Making (MCDM) methods. It uses solving and include advantages are firstly quantitative and qualitative criteria which help us in the decision making, secondly it embraces a large quantity of criteria can be considered and finally it 
constructs a flexible hierarchy can be constructed according to the problem. Therefore, the purpose of this study is to select the best and most appropriate agility test for karate using AHP method.

\section{Analytic Hierarchy Process (AHP)}

The AHP is a theory of relative measurement with absolute scales of both tangible and intangible criteria based on the judgment of knowledgeable and expert people (Ahmad \& Qiu, 2009). It is introduced by Saaty (1980) and it is one of the widely used Multi- Criteria Decision Making approach. It resolves decision-making problems by structuring each problem into a hierarchy with different levels of criteria. In other words, AHP structures a decision problem into a hierarchy and evaluates multi-criteria tangible and intangible factors systematically. AHP also has been applied in numerous fields including many software selection decisions (Forman \& Gass, 2001; Vargas, 1990; Zahedi, 1986).

This method is discussed in a number of books (Bourke, Stagnitti, \& Mitchell, 1993; Golden, Wasil, Harker, \& Alexander, 1989; Saaty, 1980). The AHP method involves four steps to solve a decision problem (Lin \& Yang, 1996; Tam \& Tummala, 2001; Zahedi, 1986). The steps are: 1) Structuring the decision problem. 2) Creating pairwise comparison Matrix. 3) Determining normalized weights and 4) synthesize the priorities. As a research question, I contend that actually there is no any specific agility test in karate and karate coaches utilize general agility tests by their own personal traits. Therefore the purpose of this research is to find the best agility test in karate by using expert opinions and AHP method.

\section{Methodology}

The AHP is a structured technique for organizing and analyzing complex decisions. Based on mathematics and Psychology, it was developed by Thomas L. Saaty in the 1970s and extensively studied and refined since then. It has particular application in group decision making and used the world in a wide variety of decision situations, in fields such as government, business, industry, healthcare, sports and education (Saaty \& Peniwati, 2008). The research methodology involved two separate phases. The phases are described as follows:

Phase 1: The first phase of this paper is formed in order to explore suitable agility tests and components of agility respectively. The instrument of data collection applied for this phase is questionnaire. By using comparison matrix that has been prepared by experts, the weights of components of agility were calculated. Having gathered data from experts the consistency was determined. If the consistency is more than 0.1 , the data must be refined until this number decrease to less than 0.1 . This phase is important because it provides the knowledge platform for the next phase.

Phase 2: The applied methodology for this phase is based on the output of phase one and the approach used is AHP. In this phase, computing weights of components of agility and also validated agility tests with respect to each components of agility was constructed. At the end of this phase, all of the components of agility and validated agility tests which had been considered were sorted.

A three level hierarchy model was used to choose the best agility test for karate.

Figure 1 shows the three-level hierarchy model. The first level presents the goal of the problem, which is to find the best validated agility test among potential candidates. As shown in the second level, the criteria of the model are divided into eight ones, namely speed, coordination, strength, reaction time, power, flexibility, balance and body mechanic. The third level consists of eight potential validated agility tests for Iranian Karatekas, which include Hexagon test, 505 test, Illinois test, SEMO test, Shuttle run test, Side Step test, T-test and Zigzag test. The tests are given at the final level of the proposed hierarchical model. In a hierarchy, the criteria are assumed to be independent among them. This is called independence case between criteria (Saaty, 1987). 


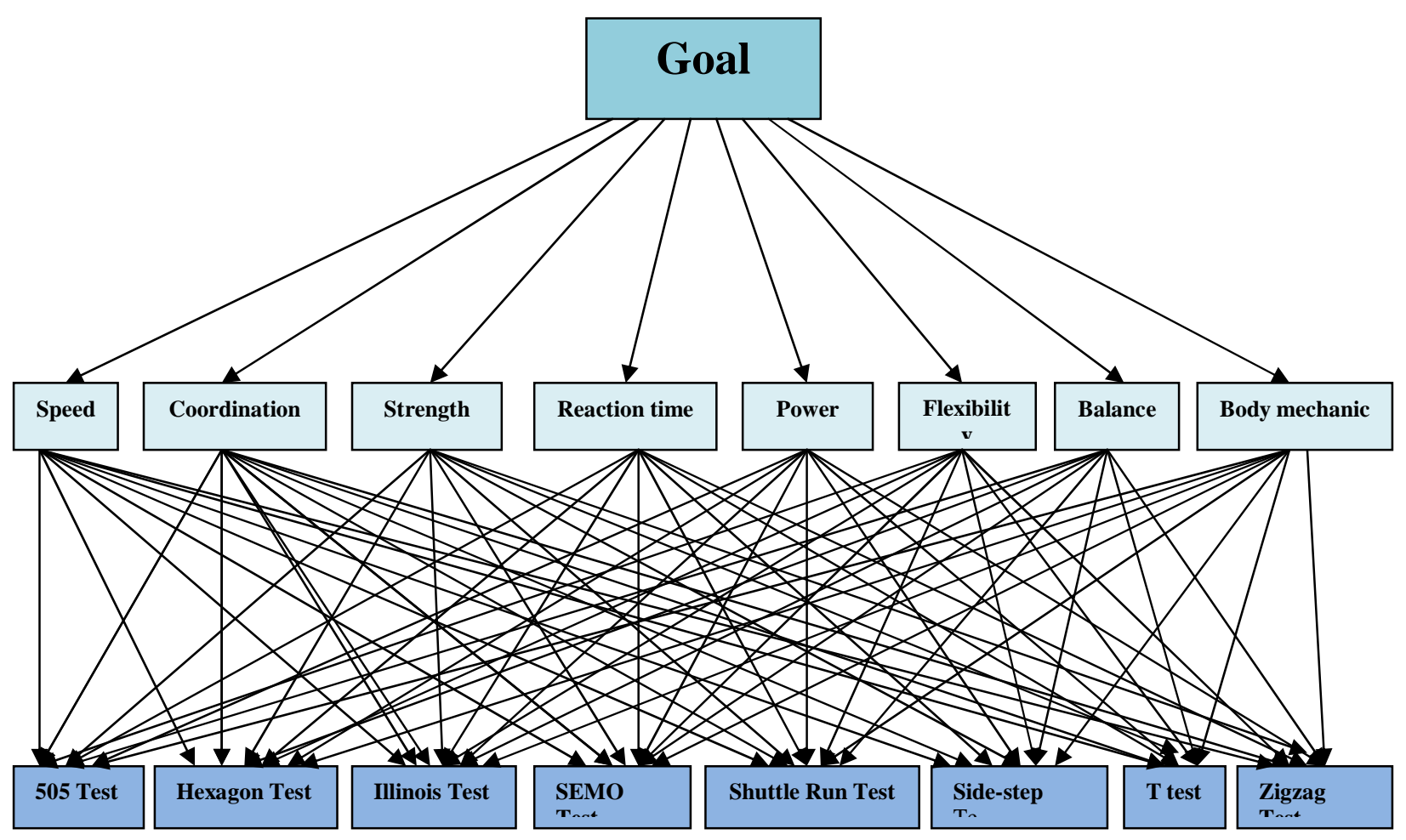

Figure 1. The Conceptual Framework of This Study

\section{Research Design}

This research employs descriptive design. The most important aim of this design is to find the best agility test among available agility tests. Descriptive research design is a valid method for researching specific subjects and as an antecedent to more quantitative studies. Although there are some valid concerns about the statistical validity, as long as the limitations are understood by the researcher, this type of study is a valuable scientific tool (Ary, Jacobs, Razavieh, \& Sorensen, 2009). In the current research, independent variable is the best agility test in karate and dependent variables are eight validated and general agility tests and their components.

\section{Population and Sampling}

All of the Iranian international and national karate coaches in various levels (i.e. youth and cadet, adults, and karate league) will be the population of this study. The population of the study should be in level of at least bachelor or higher degree in physical education and sports science. The other reason for choosing the above people as the population of this study is that they are expert and have in-depth knowledge and experience which assures reliability and validity of the tests; based on their weightings of the test components, the researchers selects the best test. That is very important because adequate knowledge can improve reliability and validity of the study (Saaty, 1996; Saaty \& Ozdemir, 2003).

Based on statistics from Iran Karate Federation (IKF) (1995), there are only 21 expert karate coaches in the country. The population has been all former karate national and international champions. Saaty (2003) indicated that the number of experts as interviewees should not be too many, and in general, five to fifteen interviewees is most suitable (Saaty, 1996). However, in the current research to increase the reliability of 
the research six expert karate coaches were chosen as the research sample. We can solve this kind of problem by using Expert Choice software and Excel. They are instrument of my research.

\section{AHP approach procedures}

The AHP approach used in this study involved several procedures. First, selecting suitable agility tests and exploring components of agility. Second, prepare questionnaire and send to expert karate coaches. Third, gathering data and data analysis. Fourth, computing consistency ratio, Fifth, Using Expert Choice software for weighting of criteria and ranking of alternatives derived from weight criteria and finally, select the best agility test based on ranking. Using AHP, the computing weights of criteria and also alternatives with respect to each criterion, should be calculated. In addition, all of criteria and alternatives which had been considered will be sorted and also the best one can be distinguished.

Comparison matrix is a part of the model structure of the analytical hierarchy process, a widely used Multi-Criteria Decision Making (MCDM) methodology. It is useful where priorities are not clear, where there are chosen due to conflicting demands on resources or are competing in importance. It is a tool that provides a framework for comparing each criterion against all others, and helps to show the difference in importance between criteria. In other words, it is used to compare each factor with each other factor, oneby-one. For each comparison, we will decide which of the two criteria is most important, and then assign a score to show how much more important it is. It can compare positive and negative criteria simultaneously. The main difficulty is to get the inconsistency of the pairwise comparison matrix obtained from the decision makers in real-world applications (Choo \& Wedley, 2004). It should be accepted, if the amount of inconsistency is less than 0.1 otherwise, the experts' opinion must be revised.

The steps of preparing comparison matrix can be generally described as follows:

Step 1: to define the problem and specify the research objective.

Step 2: to construct a squared pair-wise comparison matrix $(\mathrm{n} \times \mathrm{n})$ for criteria with respect to objective by using Saaty's 1-9 scale of pair-wise comparisons shown in Table 1.

\begin{tabular}{|cc|}
\hline Table 1: Saaty's 1-9 scale of pairwise comparisons \\
\hline Intensity of importance & Definition \\
\hline $\mathbf{1}$ & Equal Importance \\
$\mathbf{2}$ & Weak Moderate \\
$\mathbf{3}$ & Importance \\
$\mathbf{4}$ & Moderate Plus \\
$\mathbf{6}$ & Strong Importance \\
$\mathbf{7}$ & Strong Plus \\
$\mathbf{8}$ & Very Strong \\
$\mathbf{9}$ & Very, very Strong \\
\hline
\end{tabular}

The pair-wise comparisons are done in terms of which element dominates the other.

Step 3: There are $\frac{n \times(n-1)}{2}$ judgments required to develop the set of matrix in step 2. Reciprocals are automatically assigned in each pair-wise comparison.

Step 4: Synthesizing the pair wise comparison matrix is performed by dividing each element of the matrix by its column total.

Step 5: The priority vector can be obtained by finding the row averages. 
Step 6: Weighted sum matrix is found by multiplying the pair-wise comparison matrix and priority vector.

Step 7: Dividing all the elements of the weighted sum matrix by their respective priority vector element.

Step 8: Compute the average of this value to obtain $\lambda_{\max }$.

Step 9: Find the Consistency Index (CI) as follows:

$C I=\frac{\lambda_{\max }-n}{n-1}$

Where $\mathrm{n}$ is the matrix size.

Step 10: Calculate the Consistency Ratio (CR) from dividing CI on RI (Randomize Index)

$C R=\frac{C I}{R I}$

Judgment consistency can be checked by taking the CR of CI with the appropriate value in Table 2.

Table 2. Random Consistency Index

\begin{tabular}{ccccccccccc}
\hline $\begin{array}{c}\text { Order Of } \\
\text { Matrix }\end{array}$ & 1 & 2 & 3 & 4 & 5 & 6 & 7 & 8 & 9 & 10 \\
\hline R.I. & 0 & 0 & 0.52 & 0.89 & 1.11 & 1.25 & 1.35 & 1.4 & 1.45 & 1.49 \\
\hline
\end{tabular}

The CR is acceptable, if it does not exceed 0.10. If it is more, the judgment matrix is inconsistent. To obtain a consistent matrix, judgments should be reviewed and improved. In this study, these steps were carried out through the use of expert choice software. By using this software, we can rank agility tests respect to all of criteria that were applied in this paper.

\section{Procedure of Group AHP}

AHP procedure in theory has different steps as specified below:

Step 1: Structuring the decision problem. Structure the hierarchy from the top (goal) through the intermediate levels (criteria, sub-sequent levels depend on) to the lowest level which usually contains the list of alternatives.

Step 2: Creating pairwise comparison matrix.

After constructing AHP model, the priorities should be done. By priorities here we mean: weights, comparing objectives, and relative scale measurements. Weights are assigned to each criterion and sub criterion. These weights are assigned through a process of pairwise comparison. In pairwise comparison, each objective is compared at a peer level in terms of importance. In this time, a set of pair-wise comparison matrices (size $n \times n$ ) for each of the lower levels with one matrix for each element in the level immediately above by using the relative scale measurement shown in Table 1 is constructed. The pairwise comparisons are done in terms of which element dominates the other. In group AHP, the weights of each criterion for each expert should be computed in geometrical mean and the result of this step will be done in next step.

Step 3: Determining normalized weights.

Therefore, by using each pairwise comparison Matrices, weight of each row was computed by matrix of "W".

$$
C_{i j}=\frac{a_{i j}}{\sum_{k=1}^{n} a_{k j}}
$$

$$
\mathrm{i}=1,2, \ldots \mathrm{n} ; \mathrm{j}=1,2, \ldots \mathrm{m}
$$




$$
W_{i}=\frac{\sum_{j=1}^{m} C_{i j}}{n}
$$

Step 4: Synthesize the priorities.

The final step is to synthesize the solution for the decision problem in order to obtain the set of priorities for alternatives. After computing the weight of alternatives in respect to sub criteria and then sub criteria in respect to criteria and also criteria in respect to goal from step 3 (in the level immediately above), they are aggregated to produce composite weights which used to evaluate decision alternatives.

\section{Table 3. Comparing components with respect to goal}

\begin{tabular}{|ccccccccc}
\hline criteria & Speed & Strength & Power & Balance & $\begin{array}{c}\text { Co- } \\
\text { ordination }\end{array}$ & $\begin{array}{c}\text { Reaction } \\
\text { time }\end{array}$ & Flexibility & $\begin{array}{c}\text { Body } \\
\text { mechanic }\end{array}$ \\
\hline Speed & $\mathbf{1}$ & 2.44 & 0.58 & 3.14 & 0.73 & 0.51 & 3.6 & 1.26 \\
\hline Strength & 0.41 & $\mathbf{1}$ & 0.22 & 0.54 & 0.73 & 0.33 & 2.31 & 0.67 \\
\hline Power & 1.72 & 4.56 & $\mathbf{1}$ & 4.92 & 3.58 & 2.74 & 4.78 & 2.49 \\
\hline Balance & 0.32 & 1.86 & 0.2 & $\mathbf{1}$ & 0.33 & 0.39 & 1.94 & 0.62 \\
\hline Coordination & 1.37 & 1.37 & 0.28 & 3.05 & $\mathbf{1}$ & 0.59 & 2.85 & 1.63 \\
\hline Reaction time & 1.96 & 3.06 & 0.37 & 2.58 & 1.7 & $\mathbf{1}$ & 3.99 & 1.98 \\
$\begin{array}{c}\text { Flexibility } \\
\text { Body }\end{array}$ & 0.28 & 0.43 & 0.21 & 0.51 & 0.35 & 0.25 & $\mathbf{1}$ & 0.61 \\
\begin{tabular}{c} 
mechanic \\
\hline
\end{tabular} & 0.79 & 1.49 & 0.4 & 1.61 & 0.61 & 0.51 & 1.63 & $\mathbf{1}$ \\
\hline
\end{tabular}

\section{Results}

The data of this kind of Tables have been gathered from the same experts' viewpoints. Each expert fills it up and then computes the geometrical mean which has been done by authors. Consistency Ratio (CR) of matrices calculated is less than 0.1. They are gathered in Table 4 .

\section{Table 4: List of Consistency ratio}

\begin{tabular}{|cc|}
\hline \multicolumn{2}{|c|}{ Comparing agility tests } \\
\hline With respect to & Consistency Ratio \\
\hline Speed & 0.0125 \\
\hline Strength & 0.0141 \\
\hline Power & 0.0152 \\
\hline Balance & 0.0137 \\
\hline Coordination & 0.0164 \\
\hline Reaction time & 0.0155 \\
\hline Flexibility & 0.0129 \\
\hline Body mechanic & 0.0109 \\
\hline
\end{tabular}


Therefore it shows sufficient consistency. By using the matrix in this study, the inconsistency Index is calculated 0.012555 that is less than 0.1 . So indicates sufficient consistency and it is accepted.

Karate coaches make use of general agility tests to measure agility. Hence, selecting and validating karate specific agility test for assess the karatekas is essential. To this end, data was collected from 6 karate experts' opinion in order to weight and rank agility tests, especially select the best agility test for karate. After specifying relative components as criteria and also considering validated agility tests as alternatives respectively, collecting data was done in Table 3. The weights of criteria based on the group decision making was computed and showed in Table 4. The table has been completed by six karate expert's point of view in Iran. Each expert fills it up by using Table 1 separately and then by computing geometrical mean and after rounding off, Table 3 has been completed. For example in column 7 and row 6, number of $3.99(\cong 4$ ) shows that Reaction time is moderate plus importance than Flexibility and also number 4.92 $(\cong 5$ ) in 4 th column and row of 3 indicates Power is strong importance than Balance. The inconsistency Index is calculated 0.0125 that is less than 0.1 , so it shows sufficient consistency. Table 4 illustrates Consistency Ratio (CR) of matrices with respect to components of agility. In addition to Table 3, there are eight Tables as each expert should be filled them up; they are called "comparing validated agility tests with respect to each component". To illustrating clearly, we have informed one of them as Table 5.

Table 5: Comparing agility components with respect to goal

\begin{tabular}{|ccccccccc}
\hline Criteria & Speed & Strength & Power & Balance & $\begin{array}{c}\text { Co- } \\
\text { ordination }\end{array}$ & $\begin{array}{c}\text { Reaction } \\
\text { time }\end{array}$ & Flexibility & $\begin{array}{c}\text { Body } \\
\text { mechanic }\end{array}$ \\
\hline Speed & $\mathbf{1}$ & 3.37 & 1.44 & 2.82 & 2.74 & 4 & 1.94 & 1.92 \\
\hline Strength & 0.3 & $\mathbf{1}$ & 0.38 & 0.71 & 0.49 & 1.35 & 0.44 & 0.37 \\
\hline Power & 0.69 & 2.61 & $\mathbf{1}$ & 1.47 & 0.91 & 1.7 & 0.99 & 0.72 \\
\hline Balance & 0.35 & 1.4 & 0.68 & $\mathbf{1}$ & 0.65 & 1.74 & 0.87 & 0.48 \\
\hline Coordination & 0.37 & 2.03 & 1.1 & 1.54 & $\mathbf{1}$ & 2.88 & 1.47 & 1.4 \\
\hline Reaction time & 0.25 & 0.74 & 0.59 & 0.57 & 0.35 & $\mathbf{1}$ & 0.41 & 0.31 \\
\hline $\begin{array}{c}\text { Flexibility } \\
\text { Body }\end{array}$ & 0.51 & 2.29 & 1.01 & 1.15 & 0.68 & 2.47 & $\mathbf{1}$ & 0.66 \\
mechanic & 0.52 & 2.71 & 1.38 & 2.09 & 0.71 & 3.17 & 1.51 & $\mathbf{1}$ \\
\hline
\end{tabular}

As a result, based karate experts' opinion and using AHP method, the Table.6 shows that the highest weight of agility components is power with 0.30 and is followed by reaction time with 0.18 , speed with 0.14 , coordination with 0.13 , body mechanic with 0.09 , balance with 0.07 , strength with 0.06 , respectively.

Table 6: Weight of components

\begin{tabular}{cc|}
\hline Agility components & Weights \\
Speed & 0.14 \\
Strength & 0.06 \\
Power & 0.30 \\
Balance & 0.07 \\
\hline
\end{tabular}




\begin{tabular}{cc}
\hline Coordination & 0.13 \\
Reaction time & 0.18 \\
\hline Flexibility & 0.04 \\
Body mechanic & 0.09 \\
\hline
\end{tabular}

The result has been indicated as Table 7, the best validated agility test is Illinois test and it is followed by Hexagon, Zigzag, 505, SEMO, Shuttle run, T-test and Side step test respectively.

\begin{tabular}{|cc|}
\hline \multicolumn{2}{|c|}{ Table 7: Rank of validated agility tests } \\
\hline Agility tests & Ranked \\
\hline Illinois test & 0.175 \\
\hline Hexagon test & 0.165 \\
Zigzag test & 0.142 \\
\hline 505 test & 0.119 \\
SEMO test & 0.118 \\
Shuttle run test & 0.104 \\
\hline T-test & 0.102 \\
\hline Side step test & 0.076 \\
\hline
\end{tabular}

\section{Conclusion and recommendation}

In this study, the finding of the best agility test for karate was done using the AHP approach. This method was applied in this using data from a real case. To increase the efficiency and ease-of-use of the proposed model, simple software such as MS Excel can be used. The limitation of this article is that AHP ignores the uncertainty of executives' judgment during the decision-making process. Besides, some criteria could have a qualitative structure or have an uncertain structure which cannot be measured precisely. In such cases, fuzzy numbers can be used to obtain the evaluation matrix, and the proposed model can be enlarged by using fuzzy numbers. For future research, the authors suggest that other multi-criteria approaches such as TOPSIS and ELECTRE with or without fuzzy methods be used, and to be compared as justification for agility test selection in karate. The method may also be applied to other areas of sport. As a result of this paper, the best validated agility test for Iranian karatekas is Illinois test and it is followed by Hexagon, Zigzag, 505, SEMO, Shuttle Run, T test and Side Step test respectively.

\section{References}

Ahmad, N., \& Qiu, R. G. (2009). Integrated model of operations effectiveness of small to medium-sized manufacturing enterprises. Journal of Intelligent Manufacturing, 20(1), 79-89.

Ary, D., Jacobs, L. C., Razavieh, A., \& Sorensen, C. (2009). Introduction to research in education: Wadsworth Pub Co. 
Barrow, H. M. (1953). Test of motor ability for college men. Research Quarterly for Exercise and Sport, 25, 326-332.

Blaevi, S., Kati, R., \& Popovi, D. (2006). The effect of motor abilities on karate performance. Coll. Antropol, 30(2), 327-333.

Blume, D. D. (1978). Zu einigen wesentlichen theoretischen Grundpositionen für die Untersuchung der koordinativen Fähigkeiten. Theorie und Praxis der Körperkultur, 27(1), 29-36.

Bourke, G., Stagnitti, F., \& Mitchell, B. (1993). A decision support system for aquaculture research and management. Aquacultural Engineering, 12(2), 111-123.

Chelladurai, P. (1976). Manifestations of agility. Can. Assoc. Health Phys. Educ. and Recreation J, 42(3), 36-41.

Choo, E. U., \& Wedley, W. C. (2004). A common framework for deriving preference values from pairwise comparison matrices. Computers \& Operations Research, 31(6), 893-908.

Cureton, E. E. (1951). Validity. Washington, DC: American Council on Education.

Dey, S. K., Kar, N., \& Debray, P. (2010). Anthropometric, motor ability and physiological profiles of Indian national club footballers: a comparative study. South African Journal for Research in Sport, Physical Education and Recreation, 32(1), 43.

Ellis, L., Gastin, P., Lawrence, S., Savage, B., Buckeridge, A., Stapff, A., . . . Young, W. (2000). Protocols for the physiological assessment of team sport players. Physiological tests for elite athletes. Champaign, IL: Human Kinetics, 128-144.

Forman, E. H., \& Gass, S. I. (2001). The analytic hierarchy process: An exposition. Operations Research, 49(4), 469-486.

Golden, B. L., Wasil, E. A., Harker, P. T., \& Alexander, J. M. (1989). The analytic hierarchy process: applications and studies: Springer Berlin/New York.

Harman, E., Garhammer, J., \& Pandorf, C. (2000). Administration, scoring, and interpretation of selected tests. Essentials of strength training and conditioning.

Hasegawa, H., Dziados, J., Newton, R., Fry, A., Kraemer, W., \& Hakkinen, K. (2002). Periodized training programs for athletes. In: Strength Training for Sport. Ames Blackwell Science.

IKF. (1995). Iran karate Federation Retrieved 23.03.2012

Johnson, B. L., \& Nelson, J. K. (1986). Practical measurements for evaluation in physical education (Edina ed.). Edina: Burgess.

Johson, B. L. N., J.K. (1988). In practical measurements for evaluation in physical education (3rd ed.). New Delhi: Surjeet Publications.

Katic, R., Srhoj, L., \& Pazanin, R. (2005). Integration of coordination into the morphological-motor system in male children aged 7-11 years. Collegium antropologicum, 29(2), 711.

Kirby, R. F. (1971). A simple test of agility. Coach and athlete. 25(6), 30-31.

Kirkendall, D. T. (2000). Physiology of Soccer. In: Exercise and Sports Science. Philadelphia: Lipincott, Williams, \& Wilkins.

Lacy, A. C., \& Hastad, D. N. (2007). Measurement and evaluation in physical education and exercise science: Pearson Benjamin Cummings, San Francisco.

Lin, Z. C., \& Yang, C. B. (1996). Evaluation of machine selection by the AHP method. Journal of Materials Processing Technology, 57(3-4), 253-258.

Meinel, K., \& Schnabel, G. (1976). Bewegunslehre-volk und Wissen: Volselgener.

Miller, D. k. (2006). Measurement by the physical educator: Why and how: McGraw-Hill, Boston.

Pauole, K., Madole, K., Garhammer, J., Lacourse, M., \& Rozenek, R. (2000). Reliability and validity of the T-test as a measure of agility, leg power, and leg speed in college-aged men and women. The Journal of Strength \& Conditioning Research, 14(4), 443.

Pollitt, D. J. (2003). Sled dragging for hockey training. Strength \& Conditioning Journal, 25(3), 7.

Reilly, T., Williams, A. M., Nevill, A., \& Franks, A. (2000). A multidisciplinary approach to talent identification in soccer. Journal of Sports Sciences, 18(9), 695-702.

Roetert, E. P., Piorkowski, P. A., Woods, R. B., \& Brown, S. W. (1995). Establishing percentiles for junior tennis players based on physical fitness testing results. Clinics in Sports Medicine, 14(1), 1-5. 
Saaty, T. L. (1980). The analytic hierarchical process. New York: McGraw-Hill.

Saaty, T. L. (1987). Rank Generation, Preservation, and Reversal in the Analytic Hierarchy Decision Process. Journal of the Decision Sciences Institute, 18(2), 157-172.

Saaty, T. L. (1996). Decision Making with Feedback: The Analytical Network Process. Pittsburg: RWS Publications,PA.

Saaty, T. L., \& Ozdemir, M. (2003). Priority as dominance in derived measurement: invariance of the principal eigenvector. International Journal of Information Technology and Decision Making, 2(2), 185195.

Saaty, T. L., \& Ozdemir, M. S. (2003). Seven plus or minus two Math. Comput. Model, 38, 233-244.

Saaty, T. L., \& Peniwati, K. ( 2008). Group Decision Making: Drawing out and Reconciling Differences. Semenick, D. (1990). Tests and measurements: The T-test. Strength \& Conditioning Journal, 12(1), 36.

Sheppard, J., \& Young, W. (2006). Agility literature review: classifications, training and testing. Journal of Sports Sciences, 24(9), 919-932.

Tam, M. C. Y., \& Tummala, V. M. R. (2001). An application of the AHP in vendor selection of a telecommunications system. Omega, 29(2), 171-182.

Urban, P. (1993). The karate do-jo: Traditions and tales of the martial arts. Tokyo: Tuttle publishing.

Vargas, L. G. (1990). An overview of the analytic hierarchy process and its applications. European Journal of Operational Research, 48(1), 2-8.

Vescovi, J. D., \& McGuigan, M. R. (2008). Relationships between sprinting, agility, and jump ability in female athletes. Journal of Sports Sciences, 26(1), 97-107.

WKF. (1999). World Karate Federation, 2011

Zahedi, F. (1986). The analytic hierarchy process: a survey of the method and its applications. Interfaces, 96-108. 